LA.7622.SR

Status Report

Special Distribution

Issued: January 1979

\title{
Status of LAMPF
}

\author{
Louis Rosen
}

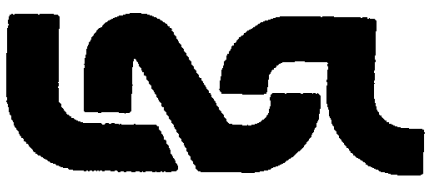


STATUS OF LAMPF

by

Louis Rosen

ABSTRACT

Crucial aspects of the LAMPF operation and its scientific programs during the past year are discussed and evaluated. This report is from a talk given by Louis Rosen at the Twelf th LAMPF Users Meeting, November 13 and 14, 1978.

The topics 1 shall summarize are schedules and budgets, safety, major accomplishments during $F Y 78$, and the status of the LAMPF organization.

Interaction of the LAMPF Users Organization with LAMPF's management has been at least as good during the past fiscal year as 1 have ever seen it. Partly, I suspect, this occurred because we are getting older and maybe even wiser. But, I think part of this better accommodation is because the Users Group Chairman, John Allred, was on site most of the year and could interact on essentially a daily basis concerning problems, ideas, and inputs from the LAMPF users and with those of us who can alleviate problems and facilitate progress. I would, tiierefore, suggest that you consider designaiing a deputy chairman of the LAMPF Users Group who is on site when the elected chairman cannot be here. You couldn't lose much by trying this scheme for a year, and you might like it.

Peter Carruthers, T-Division Leader, talked about the perhaps imminent change in LASL administration. We have gone through administrative changes before, and $I$ do not expect this change to affect, in any deleterious way, the commitments LAMPF has to the users of this facility, to the scientific community, to the Executive Branch, and to the Congress. We have commitments engraved in the Congressional Records and in your charter, and I do not see that these will be infringed by whatever happens to the LASL administrative structure. 
Peter Carruthers stated that the research budgets for LASL have been declining at an alarming rate. Here at LAMPF, we are not suffering from that malaise, at least as far as facility operation is concerned. However, only $10 \%$ of our budget goes to research, which is a minimum for LAMPF to be viable with respect to serving the LAMPF users in their research enterprises.

The past year has probably been the best ever from the standpoint of accelerator performance, beam line performance, experiments mounted, experiments completed, and budgetary history. For the first time we did not have to collect our coke bottles at the end of the year to complete our schedule; we did not have to stop procurements as we have in almost all previous years; nor did we have to curtail our activities. We managed that not by having great budgets, but by making the decision to operate this facility properly, even if we cannot run it as much as all of us would like. As a result, based on our budgets last year, we scheduled for 50\% operation in research, and we achieved it. That is $50 \%$ of all the hours in the year. We were lucky; it could have gone less well. However, our staffing level last year was such that the downtime of four months out of the year was required for maintenance. Again this year we will need all of our downtime for maintenance and for making the improvements that are critical to continuing the increase of beam intensity.

This year some very interesting, even pleasant, things occurred. The Congress, after looking at the President's budget, decided to increase the LAMPF budget by $\$ 2 \mathrm{million}$. Without the additional funds we would have had to decrease our operating schedule this year by at least $10 \%$ and probably by $15 \%$ compared to what it was last year, which would get us down to a very difficult operating level. Because of the type of facility LAMPF is, you really need to operate it as much as you can. If you get below $50 \%$ operation for research, you get into real problems, both in efficiency and morale. Also, the total cost effectiveness of the operation approaches what 1 would consider to be marginal. So the Congress saved us from a very severe fate this fiscal year. With the additional funds, we plan to increase by $10 \%$ our operation from what it was last year. However, I must add that the first month's experience this fiscal year was not very encouraging, and $I$ am not as certain as $I$ was two months ago that we can do what we are hoping to by way of increasing running time this year, but we shall try. 
Now you might wonder what this $\$ 2$ million, which is an $8 \%$ increase in budget, means by way of increasing running time if you put in all of the tactors and make all the corrections. It looks like from where we are now, an $8 \%$ increase in budget means a $20 \%$ increase in research time, which is a pretty good investment. George Rogosa worked very hard to defend this $\$ 2$ million increase against all comers. Once it became known that there was an added $\$ 2$ million in the budget, you would be surprised how many needy and worthy cases emerged to claim part or all of this $\$ 2$ million. But George Rogosa managed to defend his budget in a remarkably effective way.

It is important that LASL remain a strong, viable laboratory, but nuclear physics cannot be healthy only here at LAMPF and only in those groups that work here. It is a much broader problem. You have a right to know what my personal intervention with the office of Management and Budget (OMB) has been in terms of budgets, not for national laboratories, not for LASL, but for universities. The following two sentences are from a letter 1 wrote to Hugh Loweth, who is responsible at OMB for essentially all science and technology. I wrote this letter after I had vicited Penn State, my Alma Mater, and nuticed what was going on there in basic research.
"One result of my visit, was the startling realization that science and the training of scientists are not prospering as they should even at a really great university like Penn State. This situation, if not reversed, will make it impossible for our society to cope with the myriad of problems towards which we are accelerating at an ever-increasing pace."

I have no axes to grind, except that I have grandchildren, and from what 1 see going on in the universities, I worry about the kind of world they are likely to face. I wanted you to know how I am responding to that particular problem as 1 see it in the universities.

You may be aware that the General Accounting office (GAO) recently decided to do an in-depth audit of high-energy physics. Initially, the question was, shouldn't nuclear physics be lumped with this audit? After all, high-energy physics has something to do with the nucleus. It was decided, in view of the much lower budget of nuclear physics, that it should not be included in this first audit. First we will see how it goes with high-energy physics. They are asking some very tough questions, such as: Is the us ahead in high-energy physics? The rext question is, does it matter whether the us is ahead in high-energy 
physics? These are the types of questions being asked. The reason 1 bring it up is that there is no question but that sooner or later--and it could be sooner --somebody will realize that after the high-energy physics audit is complete (because there is some competition at the very highest levels for funds between high-energy and nuclear physics), it would not be completely unreasonable to look at nuclear physics. Well, it probably will not come for at least a year, maybe even two, but 1 think we must recognize the problems because we are spending government funds and tax funds, and we must be able to justify the resources we use. I think we can. I think we are in an excellent position to do that, but we cannot justify it by saying nothing nor by not paying attention to the course of human events and political events. I appeal to you and to your colleagues to do more than we have in the past by making the Congress, the Executive Branch, and society overall understand what we are doing and why we are doing it, and why if not we, our children, will benefit from our having done this work. We do beautiful science, but we do miserable public relations. It takes work and dedicated effort.

During FY 78, 389 visitors worked at LAMPF, representing 83 institutions, in addition to the 111 LASL people involved in experiments. One of our most persistent problems has to do with safety. Our record has been very good compared with organizations that face similar hazards. However, during the past year our lost-time accident rate has exceeded the LASL average. We have had two accidents that merited formal investigations, which take an enormous amount of time. We are devoting large resources of highly competent personnel and a large amount of money to make LAMPF a safe place to work. We have taken many safety initiatives not found at other accelerator facilities or at other LASL installations. Portal monitors are used liberally, the entrance gate to the site is monitored automatically for radioactivity in passing vehicles, and photographic recordings are made of vehicles that trigger the system. We have safety cadres in every group and in every work area, but in the final analysis it is the individual worker who determines how safe the work area is. $1 \mathrm{t}$ is essential that users participate in safety seminars, follow safety procedures, and exercise, through a designated individual, safety surveillance of all their activities. The last item is very important, and $I$ insist that it be followed, not only because 1 think it is right but also because the Albuquerque Operations Office and our LASL safety office will not let us do less. Tom Putnam recently 
initiated a safety newsletter that 1 hope all of you will read as a device to reinforce awareness of your safety responsibilicies and bring to your attention old and new safety problems. Although things are now going great at LAMPF, all this can change overnight if we fall down on our safety responsibilities to ourselves and to the public. I, for one, strongly believe that nuclear energy is absolutely vital for our future. However, we must demonstrate that we can live safely in areas close to high-level radiation. If we cannot demonstrate that, who can? Therefore, we have a nationally based reason for showing that we can really live safely in a top hazard facility like LAMPF.

I will talk briefly about some of our major accomplishments during the last fiscal year. You will hear from Don Hagerman about some of our major accelerator-related accomplishments during the past year. Lew Agnew, Bob Macek, and Arch Thiessen relate similar progress in the development of the experimental areas. In fact, it is in these latter areas that 1 see our most severe challenges in the future as we press ever harder toward material and fabrication methods that can withstand very high levels of radiation and severe cyclic heat loads. The latter is not much less important than the former.

For most of us in this room, our major concern is now the research program, and our progress has been very impressive. Very tough, but really exciting and crucial, problems have been addressed with good success in many areas including nucleon-nucleon and pion-nucleon interactions, pion nucleus studies, rare decay modes of pions and muons, muonic and pionic atoms, single and double charge exchange, muonium hyperfine structure, lepton conservation, etc. We have not fallen down badly on any of cur major initiatives in research so far. We have an internal report available, prepared at Enloe Ritter's suggestion, on work in progress during FY 78 .

This is primarily a basic research facility. However, one of our strong points, and $I$ suspect one that was influential in persuading the congress to increase our budgets for this fiscal year, has been the practical applications that we are pursuing. Dr. Jose Sala will discuss the biomedical applications relating to pion therapy. I am very encouraged and enthusiastic about that program. There are other programs that I think are equally important, such as the isotope production program and the radiation damage program. Also, the Weapons Neutron Research (WNR) facility is an interesting and new development. Many of you will remember that we requested WNR some years ago. A major basis for that 
request was not so much the basic neutron physics work that could be done, but the fact that sooner or later a test ban may be government policy. When that happens, we suggested that it would be extremely valuable to this country to have a hardware capability that retains the highiy specialized and very competent people on whom the nation depends for its nuclear weapons development and nuclear defense security. That argument was persuasive, and WNR is a reality--it is operational. However, as the years went by, it appeared that one could enhance greatly the effectiveness of WNR for that program if one nad a proton storage ring (PSR) whereby one could bunch the beam, thereby increasing iritensities and repetition rates, and do all the good things you would like to do in time-offligh: programs. I have strongly supported the PSR at the highest levels of government. In the meantime it appeared that pulsed neutrons of the intensities that could be obtained already with WNR and that will be even more accessible with the PSR could be extremely important in solid-state physics, and other condensed matter science, for a national capability that exceeds that available from reactors in this country. The story of why this is so is very long and complicated. If you are interested, I can tell you about it or write a report about it. Nevertheless, you now see three efforts under way to develop highintensity pulsed neutron sources, based on spallation reactions induced by about 800-MeV protons of high intensity; one at the Rutherford Laboratory, one at Argonne, and one here. Also, the Soviets have decided to build a facility similar to LAMPF, with very high intensity. Their initial capability will, in fact, be in the neutron area. To start with, they will build a storage ring. We now have two eminent visitors from the USSR who tell me that although the project is now recognized as one that deserves strong support in the Soviet Union, the progress has not been as rapid as they would like. However, this facility should be completed in the next five ur six years. They hope, of course, that it will be built sooner. We have had two delegations within the last several months from the USSR looking at how we built and how we operate our facility. Another even larger delegation, who will stay longer, is due here on the 16th of November. They are very serious about this project and, you know, if there is a test ban, they have to be one of the parties to it. My guess is that they too will be nervous about agreeing to such a ban if they do not have the means to maintain a high level of capability in the national defense arena. 
When John Deutch started looking at the funds for making available this pulsed neutron capability for condensed matter physics, he confronted the question of funding, as he must do. The program at Argonne, called IPNS-1 (intense pulsed neutron source-1), was going ahead, but there was a proposal for a much more expensive IPNS-II. John Deutch suggested that we look into the possibility of upgrading the storage ring capability at LAMPF so that it would be as capable as IPNS-II or the Rutherford accelerator now being built. Several studies were made by $P$ and AT Division, with somewhat less work being done by MP Division, to respond to Deutch's suggestion. We found that LAMPF could make $400 \mu A$ of beam available for the pulsed PSR. However, this comes with some penalty to the rest of the research program; you have to somehow share this $1000 \mu \mathrm{A}$, and the way you share it is by way of duty factor. On the other hand, we have promised (documented in the Congressional Record) that up to 10\% of the LAMPF beam (LAMPF duty factor) will be devoted to the WNR facility. It is almost the law of the land. But what about going from $10 \%$ to perhaps $40 \%$ of the LAMPF duty factor for work other than the main purposes for which LAMPF was authorized? After John Deutch talked with me about this and understood that there was a possibility of doing this but that there were penalties, the first thing that happened was it a: Jim Kane asked me to determine how the LAMPF users would react to sharing the beam with PSR. I called together the Board of Directors of the LAMPF Users Group and solicited their advice on how such a diversion of duty factor might affect your program. The Board of Directors made their recommendations predicated on John Deutch's offer to provide funds for increasing LAMPF operations so as to make up for the lost beam time in additional running time of the accelerator. I am not sure righ: now whether we can run this accelerator much more than what is already planned for this fiscal year. However, John Deutch was so interested in meeting our commitment to you that he is willing to provide the funding necessary for operating the accelerator seven or eight months instead of six. The users' response was that although they are not wild about giving up $40 \%$ of the duty factor, it is for a good national cause, it will make a very fine solidstate physics facility, and they think they can live with it.

I sent the users' response to DOE along with my personal recommendation, which had nothing to do--at least not directly--with what the users felt they could or could not live with. I want to tell you what my recommendation was because you will hear several versions of this as time goes on and what effect 
it has, if any, on John Deutch's decision as to where he is going to put the resources to develop this solid-state physics facility. I quote from my letter:
"My recommendations to you, thenefore, are that one should proceed with the development of IPNS-1, with the upgrade of WNR to $100 \mathrm{\mu A}$ capability and with the construction of a storage ring at WNR which can accept from LAMPF $100 \mu \mathrm{HA}$ of $\mathrm{H}^{-}$beam. Following completion of IPNS-I and PSR one should expand the research program to exploit these powerful facilities and concurrently learn whether still high- er intensity would be worth the additional cost and effort. I read the academy report which was the basis for going to five times this intensity, and I could not see in that report nor could I learn írom people--knowledgeable people to whom 1 talked--of any real urgency from the standpoint of physics to right now go to the very top intensity we can foresee in the next 10 years. At the same time, the Rutherford synchrotron will yield information on the intensity to which one might realistically aspire with IPNS-II while the 100-uA PSR would tell us how and at what cost one might push this intensity to the highest value that is feasible. So there you have my recommendations."

I do not know whether they will follow my recommendations, but I wanted you to know that 1 did not propose shutting down IPNS-I nor did I propose that one facility serve the entire nation. Budgetary factors may rule that another course, other than the one I recommended, is more appropriate. In my recommendations I stated that we must build the storage ring so that, if its performance is upgraded to $400 \mu \mathrm{A}$, it can be done without ripping the whole thing out and starting again.

Now back to practical applications. We are very proud of one of our people, Danny Doss, who received an award for making one of the top 100 contributions to technology in this country for the past year. This contribution was something 1 believe 1 alluded to a year ago. We have been working on a system for localized $r f$ heating. It was an outstanding development and is now being used to treat cancer eye in cattle with high probability of success--like $90 \%$. For this achievement, Danny received what, I thought, was appropriate recognition.

I will review some of the new capabilities that have come on-line since our last meeting. These include higher resolution at both HRS and EPICS; operational polarized ion sources; polarized hydrogen targets; $\pi^{0}$ spectrometer was built, rebuilt, and put into use; and WNR started to function. To me the use of a $\pi^{0}$ spectrometer in a pion laboratory is similar to that of a neutron spectrometer in a basic nuclear physics laboratory. It is a very basic instrument that I believe will be successful in single-charge-exchange experiments as well as in other experiments. 
We continue to involve the scientific community in the governance of LAMPF and in determining our future course. Based on a one-year study, the Committee on Future Facilities for LAMPF, headed by Dave Lind, made several recommendations. If you have reservations about these recommendations, there is still time to talk to Dave Lind and the Committee about getting them changed. Their recommendations and our initial responses are as follows.

The Committee supports variable energy operation--the Hagerman plan--but recommends that when feasible, low-energy operation rather than the Hagerman plan be used. Further exploration of other variable energy methods should be continued. We are committed, since 10 years ago, to variable energy operation and, since a few months ago, to implementing this within a year, hopefully sometime next summer. So we are following that recommendation. We will use whatever plan seems most feasible at the time we begin these experiments, based on the energy at which we operate. If there are a group of experiments at HRS, EPB, and Line $B$ that require $750 \mathrm{MeV}$, and if we can run the whole facility at $750 \mathrm{MeV}$ and use that beam all the time, certainly we will try to do this. But right now 1 think it is premature to make promises about what the tactics will be. The strategy is clear, but we have to worry about the tactics.

The Committee proposes that a library-lounge area be built to encourage the exchange of ideas between staff and users. Although 1 agree that we need a library-lounge, it is very hard to build something even that simple out of operating funds, but we will work on it.

The Committee requests that LAMPF establish a group of staff members whose primary activity will be to design and make feasibility studies on future accelerator facilities at LASL. The Technical Advisory Panel (TAP) will also set up a committee that will study the future needs of medium-energy physics and will provide input for laboratory studies. Of course, that is a staffing problem and a budgetary problem, and $I$ think it will probably be next fiscal year before we can hope to set up a long-range planning committee.

The Committee strongly endorses a design study for a pion-muon channel. Macek's group hopefully will find the resources this fiscal year for the study.

The Committee recommends formation of a group at LAMPF that will conduct, develop, and mairtain polarized targets and be capable of innovations. Although we now have such a group, they have not had the resources available for innovation. However, once they finish with what we need right now, such as standard 
equipment, and they have the resources above those needed for target maintenance, 1 believe this group can provide the innovations that are proposed.

The Committee recommends that LAMPF strengthen its detector development effort. Here I do not know quite what to do. Our policy has been to support good ideas on detector development. I think to set up a group to develop detectors is not appropriate because of our limited resources, nor am 1 convinced that this is the right way to go. Because in this area 1 have a difference of opinion with the Committee, I would like to know what your thoughts are.

The Committee recommends that the following tasks be pursued, with priority in the order listed: (1) polarized targets, (2) $12 \%$ duty factor, and (3) detector development. The TAP also assigned priorities to several major projects: pion-muon-channel design study, library-lounge, building addition to EPB, and nucleon-nucleon spectrometer. These are all difficult projects. The building addition to EFB is a costly undertaking, and we will have to ask the Committee whether there are other ways of achieving their objectives. Eventually, we probably will have to increase that building area. The Committee knows that efforts toward a high-intensity source for the polarized beam is being built; otherwise, it would have been a high-priority item also. One other major recommendation, the $\pi^{0}$ spectrometer modifications, received consideration. The feeling is that it should be deferred pending on-going tests of the current spectrometer. I think this was, in fact, the plan.

Next August we will conduct a 10-day workshop on LAMPF program options in basic research. We are in a very good situation now. The other meson facilities are operational, we know about what we can expect at these meson facilities, and we know what the electron machines can do. Therefore, this looked like an ideal time to gather together some of the best people and ask some hard questions. Namely, what are the best goals for the next 5 to 10 years likely to be? The following are four of the questions to be addressed.

(1) What are the important physics topics that might be understood through research on these accelerators in the next 10 years? These topics include, but are not restricted to, fundamental interactions and symmetries in particle physics, and nuclear modes of motion, structure, and reaction mechanisms.

(2) What experiments should be undertaken to carry out the program? What are the kinematical conditions, accuracies, resolutions, and other parameters required to obtain the desired knowledge? 
(3) Which accelerators are best suited for each experiment? What work at other laboratories (low, intermediate, or high energy) could be undertaken to complement and/or supplement the proposed LAMPF program? What should LAMPí do to complement and/or supplement the programs at other accelerators?

(4) What new facility capabilities should be explored for the long-term future?

I tem no. 4 is a very important question that we must begin to address now if we are going to do anything in the 1990s. Everyone is invited to the plenary sessions of this workshop. In fact, we have budgeted funds to support some students and a few post-docs to attend these sessions so that they can intelact with others on the decisions made about their future. Submit your list of nominees to John Allred, Conference Coordinator. I should also mention that Earle Lomon, Program Chairman, has worked very hard on this workshop. He has spent some time here and at MIT working on program plans. We have a very good program committee that has been supporting his efforts. I think you will all agree that the choice of Ernie Henley as Conference Chairman is as good as one can do. I anticipate a very interesting and productive workshop. It is scheduled for the last 2 weeks in August, immediately following the TRIUMF meeting so that some of the people from overseas can participate in both meetings. The workshop will be organized into a set of twelve panels dealing with particle and nuclear physics: ( $P-1)$ strong interactions, $(P-2)$ weak interactions, $(P-3)$ neutrino-induced interactions, and $(\mathrm{P}-4)$ exotic atoms and electromagnetic interactions. Set $\mathrm{A}:(\mathrm{N}-1)$ nuclear densities and dynamic characteristics, $(N-2)$ elementary excitations, (N-3) correlations in nuclei and high-momentum components, and ( $N-4)$ meson degrees of freedom and propagation in nuclei. Set $B$ : $(N-5)$ weak and electromagnetic interactions in nuclei, $(\mathrm{N}-6)$ nucleon-nucleon and pion-nucleon interactions withi. nuclei, $(\mathrm{N}-7)$ pion absorption and production mechanisms, and $(\mathrm{N}-8)$ high-momentum transfer reartions at high resolution.

All indications are that the LASL central computing facility (CCF) cannot fulfill all your computer needs, so we are developing a computer capability for data analysis. We will soon have a committee, chaired by Hal Butler, that will lay out the structure of computing capability at LAMPF for the next 5 to 10 years. We have been promised some funds for medium-size computers that will handle most of what we now do at the CCF. In fact, we have funds this fiscal year to build 
a computer building. There have been several workshops regarding this computer facility in which many of you participated. Although we are following your recommendations on how to proceed, I hope that you will participate in providing wee: ly input on how this should evolve.

One problem most of you do not worry much about, and for good reason, is the overali healih of the LAMPF organization. That involves much more than budgets, beam line:, and experiments. It involves people, morale, enthusiasm, and competence. The LASL administration made a laboratory-wide survey in which more thon $90 \%$ of the lab employees participated. Included in the survey were questions about the employees' attitudes toward their supervisors, their work, their work place, and their environment. I have chosen a few survey items to give you an idea of some of the management problems we have to cope with, which normally you need not be aware of and probably are not aware of.

In Figs. I and 2, MP Division was rated very high. Although our work areas are crowded, our people responded favorably to their working conditions.

Figure 3 shows that most people want their salary increases to depend on how well they are doing and not on their age or how long they have been here. Those who say they would like general raises are at the far left of the figure. Ninety percent of those responding said they preferred merit increases, and $10 \%$ said they would like their raises determined by something other than a perception of how well they are doing.

Figure 4 is more complicated, but again MP Division ranks fairly well. Remember that there are times when you ask people to work on a new experiment. The employees have never seen what you are doing nor have they had any training for that experiment.

Figure 5 shows that MP Division ranked very low in terms of how many people are satisfied with the amount of work they have to do.

Frances Menlove provided us with other statistical breakdowns that she thought we would find interesting. Figure 6 shows how MP Division personnel respond to supervisory variables and their appraisal of these variables. One dot means that MP ranks in the top 50 th percentile; two dots means we rank in the top 25 percent.

Incidentally, the Chairman of the Board of Varian, during a recent visit, asked me how our budget compared with that at the Stanford Linear Accelerator (SLAC). When I told him what it was, his response was that he could not see how 
we ranaged on such a low budget. I hope somebody is listening. At the recent Asilomar Conference, there was a discussion on how federal support is going to university accelerators and to university groups compared to that of the national accelerators and national groups. In view of that, 1 asked Don Hagerman to pulse his computer for some statistics. Remember that our promise to the Congress and then the AEC was that about $50 \%$ of beam time at LAMPF would be used at LASL. That was agreed upon as a very early condition of putting a national facility at this Laboratory. What we did was to multiply the participants involved in a given experiment by the beam hours they realized--for MP Division, other LASL divisions, universities, and other users (Table 1). The fiqures show that LASL usage is, in fact, about 40\%. You can make sizeable differences in these numbers by deleting some activities, such as the isotope production facility, where essentially only LAS: is involved. Table 11 shows you what happens if you take out a few of the very heavily used facilities, such as neutrino, radiation darage, isotope production, and thin target area. By deleting those facilities, the universit es and "other" get $66 \%$ and the rest goes to LASL. Here, again, we are honorinn our commitment made to the scientific community. Our most precious resource is our graduate students. At a discussion during the Asilomar Conference, there was some concern expressed that graduate students at large facilitics do not have adequate opportunity for a broad education and that their activities are too narrowly confined to data taking on a single experiment. Although there was some refutation of this concern, mainly by LAMPF users, this is an area where improvements can be made. At LAMPF, graduate students have the opportunity, with approval of their advisor and their university, to work part-time on activities not related to their thesis. This is intellectually healthy and economically useful. In addition, LAMPF graduate students have recently organized so that they can more easily and coherently interact with LAMPF management. They now sponsor seminars and short courses by eminent scientists. I think it is important to your students and our country that the students be encouraged to participate in these activities. 


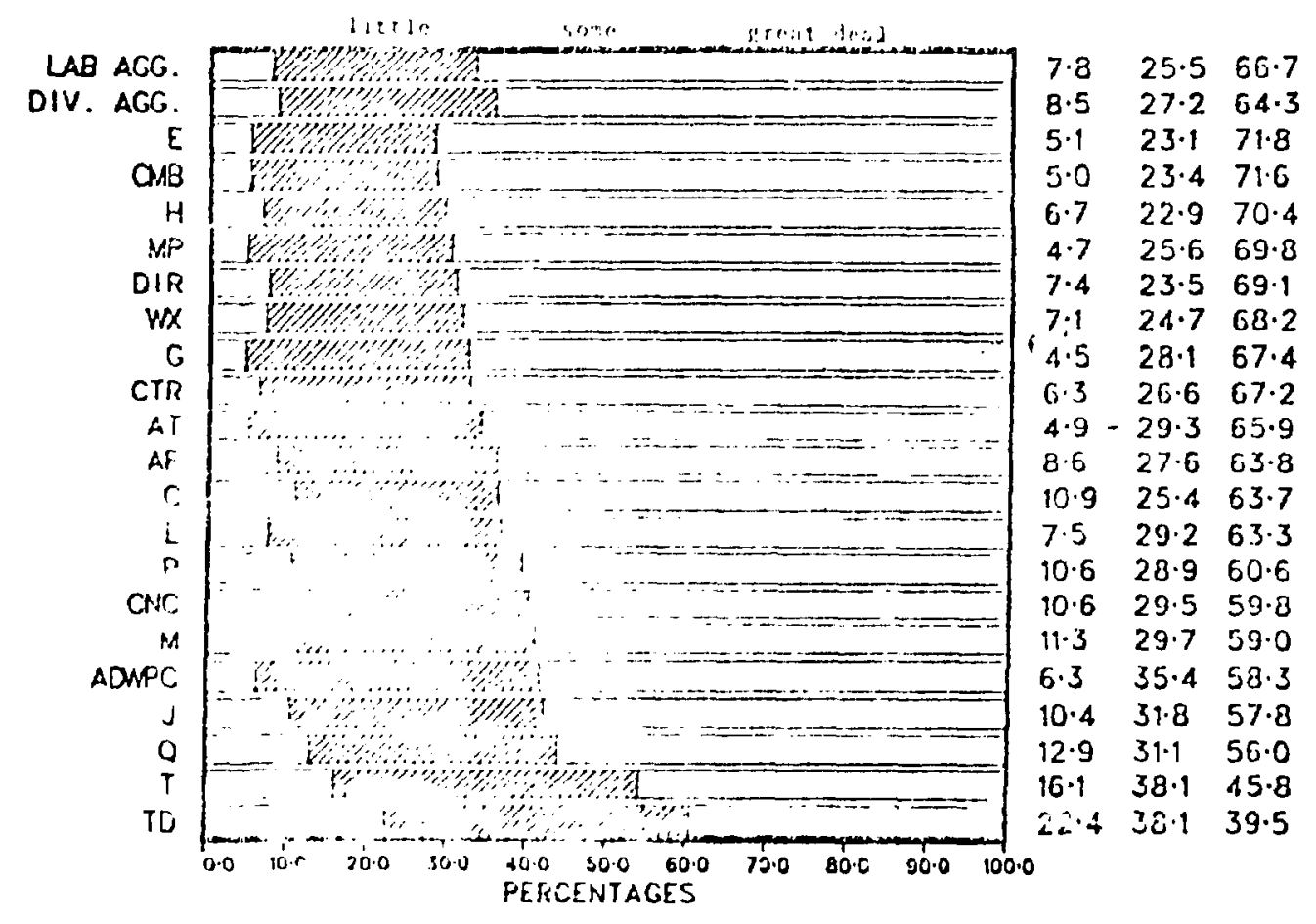

Fig. 1. Response to level of pride in appearance of work area.

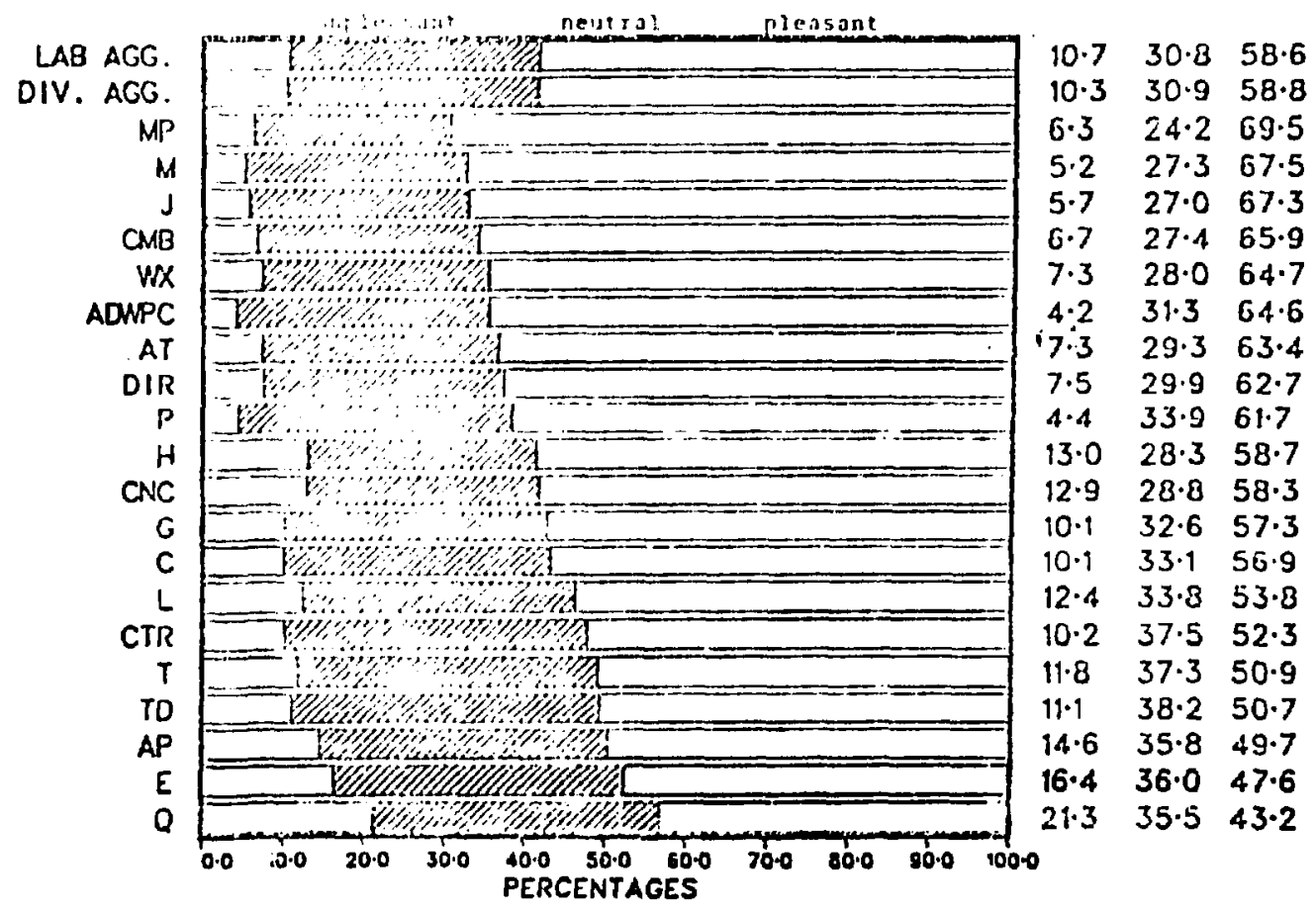

Fig. 2. Response to personal attitudes based on physical working conditions. 


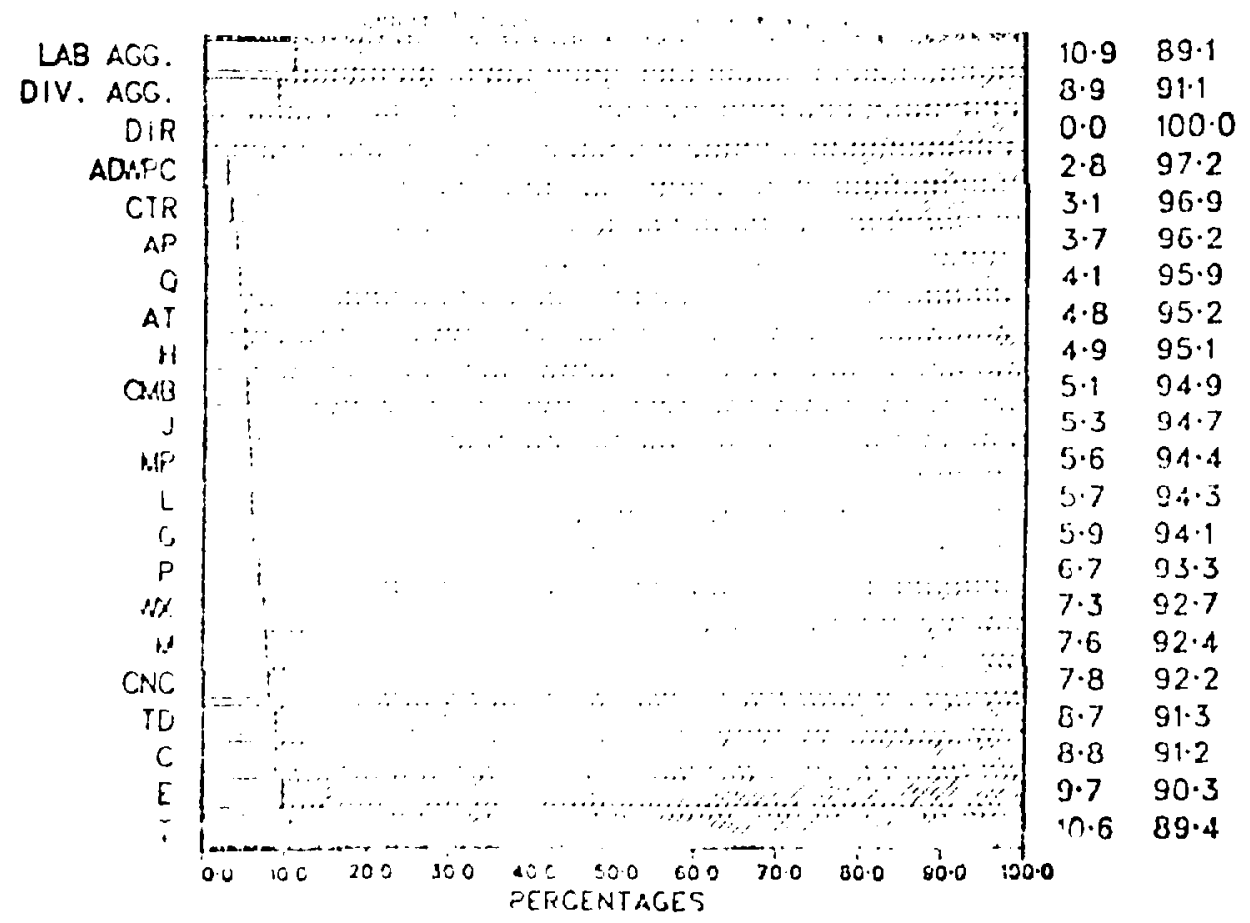

Fig. 3. Respune the wins sheuld be determined (general vs merit).

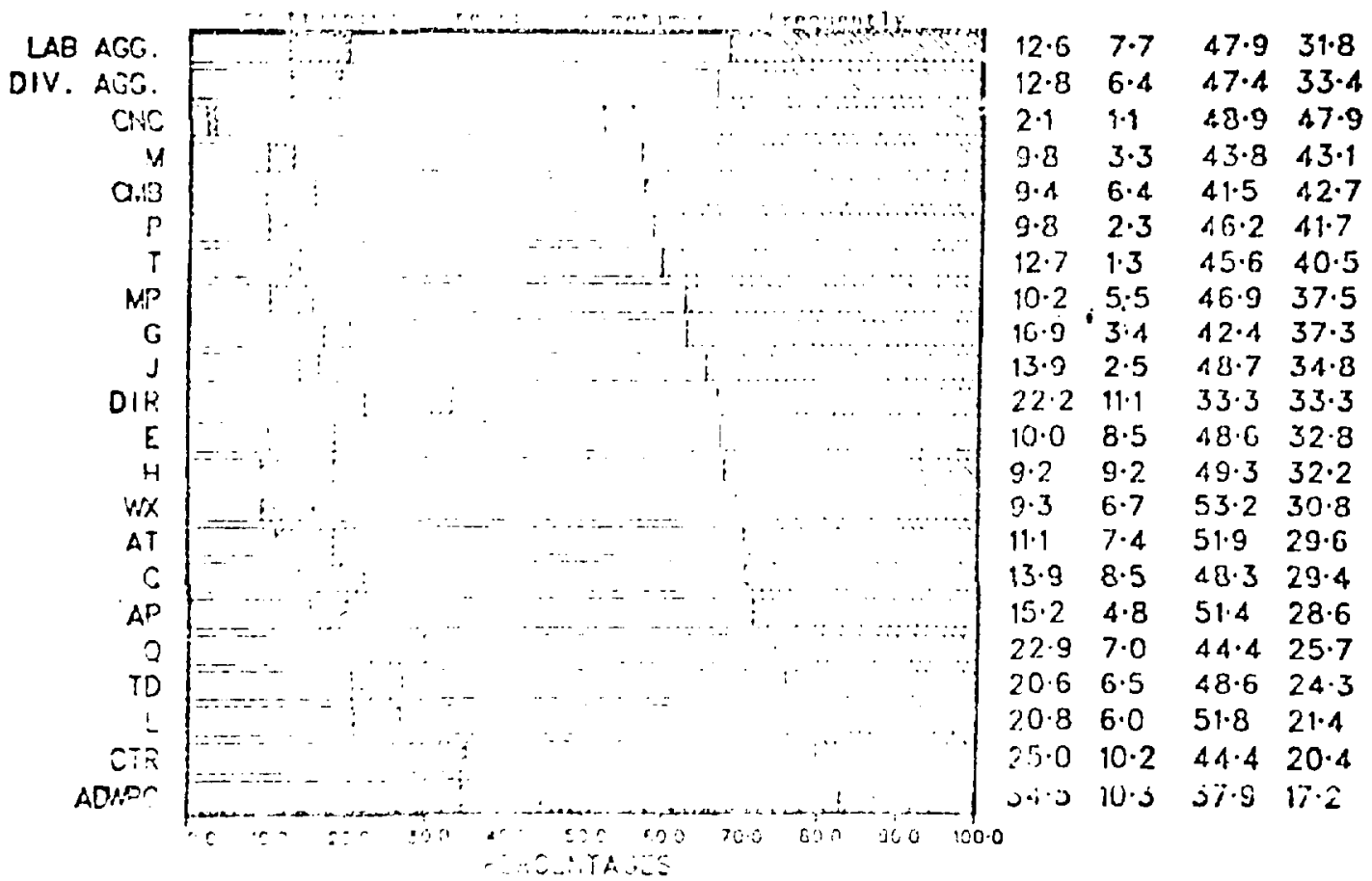

Fig. 4. Response to dmount of job training given to new employees. 


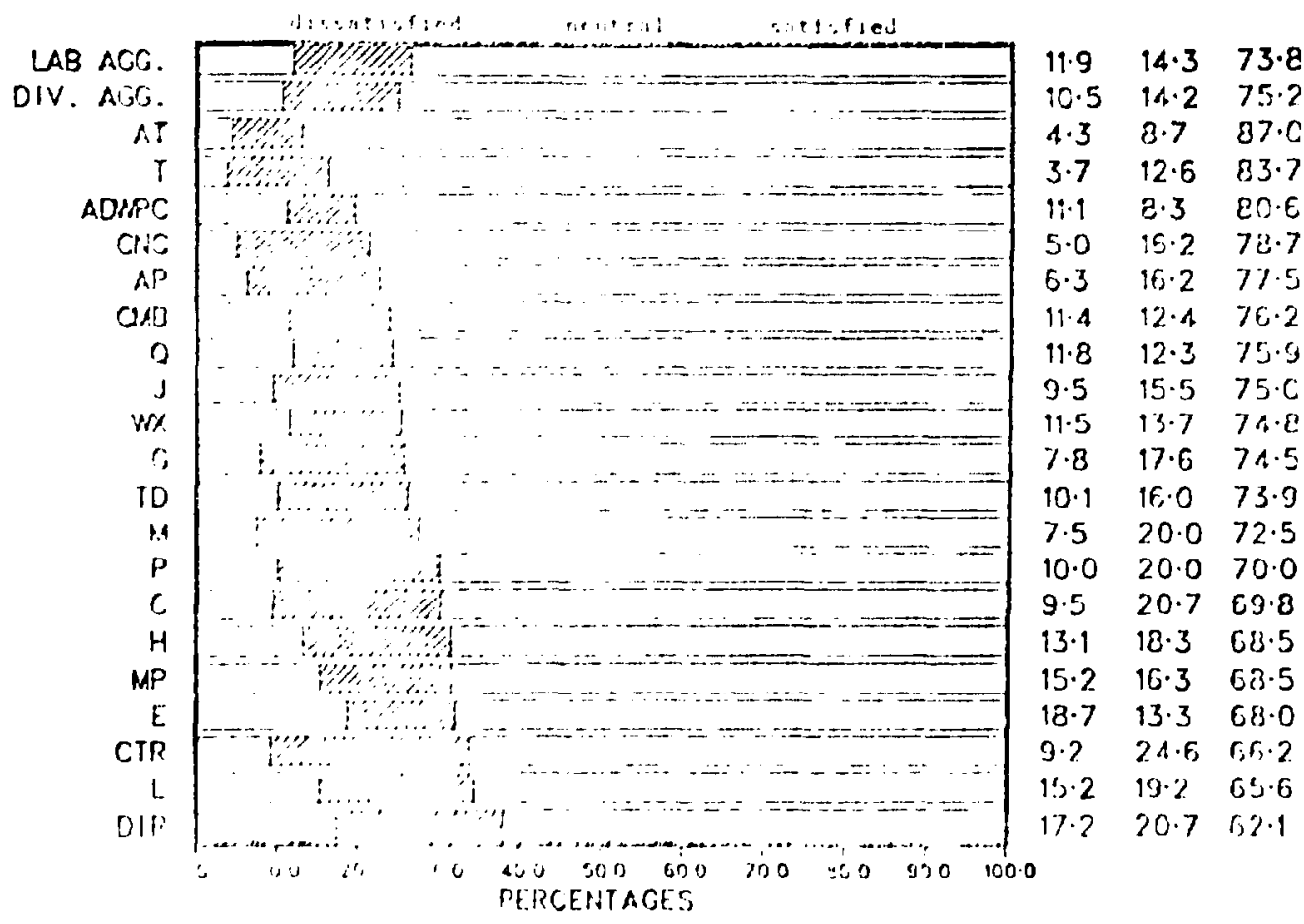

Fig. 5. Response to degree of satisfaction on amount of work done by employees.

\section{MP High on Positive Supervisory Variables}

My Supervisor

is always fair with subordinates

keeps subordinates informed

doesn't let employees get away with too much

has respect of subordinates

encourages subordinates to speak up

MP High on Positive Performance Appraisal Variables

My Supervisor

praises good work

rewards me for good performance

does good job of judging my performance

keeps poor performance from getting rewarded
Staff

$\therefore$

$\therefore \div$

$\therefore$

$\therefore$

$x+$

Fig. 6. Responses to attitudes about supervisory staff. 
TABLE I

BEAM TIME PARTICIPANTS AT LAMPF

\begin{tabular}{lcc} 
Category & $\begin{array}{c}\text { Participants } \\
\times \text { Beam Hours }\end{array}$ & z of Total \\
\cline { 2 - 3 } MP & 42298 & 23 \\
Other LASL & 32455 & 18 \\
University & 82312 & 44 \\
Other & 25353 & 14
\end{tabular}

TABLE | |

KINDS OF EXPERIMENTS AT LAMPF

Number of Participants

$$
\text { other }
$$

Experiment MP LASL Univ. Other

31 (Neutrino) $4 \quad 24$

45 (Radiation 6

namage)

267 (1 sotope 4

Production)

308 (Thin Target 1113 Area)

We $f$ ind that the weighted percentages then are 